\title{
SEVERITY OF TRAUMA VICTIMS ADMITTED IN INTENSIVE CARE UNITS: COMPARATIVE STUDY AMONG DIFFERENT INDEXES
}

Lilia de Souza Nogueira ${ }^{1}$ Regina Marcia Cardoso de Sousa ${ }^{2}$ Cristiane de Alencar Domingues ${ }^{3}$

Nogueira LS, Sousa RMC, Domingues CA. Severity of trauma victims admitted in intensive care units: comparative study among different indexes. Rev Latino-am Enfermagem 2009 novembro-dezembro; 17(6):1037-42.

This study compared the performance of the Injury Severity Score (ISS) with the New Injury Severity Score (NISS) and also the Simplified Acute Physiology Score II (SAPS II) with the Logistic Organ Dysfunction System (LODS) in trauma victims, in order to predict mortality and length of stay in Intensive Care Units (ICU), besides identifying which indexes have been the most effective to estimate these results. A retrospective analysis was done in the records of 185 victims admitted in ICU between June and December 2006. None of the four indexes properly discriminated the patients according to length of stay at the ICU. The ISS and the NISS did not show a good discriminating capacity in case of death, but the SAPS II and the LODS presented good performance to estimate mortality at the ICU. Results pointed towards the use of SAPS II and LODS when trauma victims are admitted in an ICU.

DESCRIPTORS: intensive care units; wounds and injuries; trauma severity indices; severity of illness index; mortality

\section{GRAVEDAD DE LAS VÍCTIMAS DE TRAUMA, ADMITIDAS EN UNIDADES DE TERAPIA INTENSIVA: ESTUDIO COMPARATIVO ENTRE DIFERENTES ÍNDICES}

Este estudio tuvo por objetivo comparar en víctimas de trauma el desempeño del Injury Severity Score (IS), con el New Injury Severity Score (NIS) y, también, del Simplified Acute Physiology Score II (SAPS II), con el Logistic Organ Dysfunction System (LODS) para predecir la mortalidad y el tiempo de permanencia en unidades de terapia intensiva (UTI), y también para identificar cuales índices fueron los más efectivos para estimar esos resultados. Fue realizado un análisis retrospectivo de las fichas de 185 víctimas, admitidas en una UTI, entre junio y diciembre de 2006. Los cuatro índices no discriminaron adecuadamente a los pacientes según el tiempo de permanencia en la UTI. EI IS y el NIS no mostraron una buena capacidad discriminatoria para la ocurrencia de muerte, diferente del SAPS II y del LODS que presentaron un mejor desempeño para estimar la mortalidad en UTI. Los resultados apuntaron para el uso del SAPS II y del LODS cuando víctimas de trauma son internadas en una UTI.

DESCRIPTORES: unidades de terapia intensiva; heridas y traumatismos; índice de gravedad del trauma; índice de severidad de la enfermedad; mortalidad

\section{GRAVIDADE DAS VÍTIMAS DE TRAUMA, ADMITIDAS EM UNIDADES DE TERAPIA INTENSIVA: ESTUDO COMPARATIVO ENTRE DIFERENTES ÍNDICES}

Este estudo objetivou comparar em vítimas de trauma o desempenho do Injury Severity Score (ISS), perante o New Injury Severity Score (NISS) e, também, do Simplified Acute Physiology Score II (SAPS II), perante o Logistic Organ Dysfunction System (LODS) para predizer a mortalidade e o tempo de permanência em unidades de terapia intensiva (UTI), além de identificar quais índices foram os mais efetivos para estimar esses desfechos. Foi realizada análise retrospectiva dos prontuários de 185 vítimas, admitidas em UTI, entre junho e dezembro de 2006. Os quatro índices não descriminaram adequadamente os pacientes segundo tempo de permanência na UTI. ISS e NISS não mostraram boa capacidade discriminatória para ocorrência de óbito, diferente do SAPS II e LODS que apresentaram melhor performance para estimar a mortalidade em UTI. Resultados apontaram para o uso do SAPS II e do LODS quando vítimas de trauma são internadas em UTI.

DESCRITORES: unidades de terapia intensiva; ferimentos e lesões; índices de gravidade do trauma; índice de gravidade de doença; mortalidade 


\section{INTRODUCTION}

Today, global advances in technology and violence are contributing to the rising number of deaths or disabilities due to traumas. To improve care delivery to these victims, trauma severity indices have been created which, through uniform language, permit assessing the severity of anatomic injuries and the trauma population's probability of survival. These scoring systems make it possible to assess care delivery, plan emergency care and document epidemiological characteristics. Indices include the Injury Severity Score (ISS), developed as a result of the acknowledged fragility of the Abbreviated Injury Scale (AIS) as a prognostic measure for patients with multiple injuries ${ }^{(1)}$.

The AIS determines the individual severity of injuries in trauma victims, but does not assess the cumulative effect of multiple injuries in different body regions, which are common in severe trauma patients. The ISS attempts to picture trauma victims' global severity and consists of the sum of highest squared score of three different body regions where the most severe traumas are located, according to the AIS code. The higher the score, which can range from 1 to 75 points, the greater the trauma severity and, hence, the greater the probability of death ${ }^{(1)}$.

Errors were identified when applying the ISS to multiple injury patients, located in the same body region, as this index only considers the most severe injury, ignoring the second and third most severe injuries, which are often located in the same body segment as the first. To correct this distortion, the New Injury Severity Score (NISS) was created, whose score is obtained by adding up the squared AIS scores of the three most severe injuries, independently of the body region ${ }^{(2)}$.

Due to their severity and high complexity, many trauma victims need to be admitted to intensive care units (ICU). These units increasingly use severity indices due to their importance to assess the unit's performance and the efficiency of the applied treatment.

The Simplified Acute Physiology Score II (SAPS II) is a standardized and internationally accepted system to assess the severity and prognosis of patients hospitalized in ICU. Twelve acute physiological variables are scored, besides age, admission type and presence of a chronic disease. The final score, converted through a logistic regression equation into probability of hospital mortality, results from the sum of variable scores, with higher scores corresponding to more severe patient conditions ${ }^{(3)}$.

The Logistic Organ Dysfunction System (LODS) also permits the identification of hospital mortality probability, focusing on patients' organ dysfunction during their first day of hospitalization at the ICU. Physiological variables are used and, by quantifying the severity of the organ dysfunction, the probability of hospital mortality can be identified ${ }^{(4)}$. Facility and similarity in the application of these indices, besides their international recognition, were decisive to choose the indices used in this research.

A historical analysis of scientific research published in this journal revealed that only two articles had comparatively analyzed trauma severity indices, one of which was a literature review ${ }^{(5)}$ and the other original research ${ }^{(6)}$, which strengthens the importance and contribution of this study to the scientific community.

Moreover, until data, no research has been located in literature which compares the predictive capacity of the ISS, NISS, SAPS II and LODS for mortality and length of stay of trauma victims admitted to ICU. This research aimed to make this comparison and, thus, identify which of these severity indices performs better to estimate mortality and length of stay of trauma victims admitted at ICU.

\section{MATERIAL AND METHODS}

An exploratory, descriptive, retrospective field study with a quantitative approach was developed, involving patients hospitalized at the ICU of the Hospital das Clínicas at the University of São Paulo Medical School (HCFMUSP), between June 1st and December 31st 2006.

The inclusion criteria adopted to select the sample were as follows: being 18 years of age or older, being a victim of blunt or penetrating trauma, being hospitalized at the ICU for more than 24 hours and being admitted to hospital within 48 hours after the trauma occurred.

Four instruments were elaborated to guide data collection from the patients' files: the first permitted the recording of patients' characterization data, departure conditions from the ICU (discharge, death) and length of stay at the unit; the remaining instruments were used to compile the variables 
included in the calculation of the SAPS II and LODS, to list the descriptions of injuries resulting from the trauma and to calculate the ISS and NISS.

After approval by the Ethics Committee for Research Project Analysis - CAPPesq (Protocol No 0168/07), the files of patients hospitalized at ICU were requested from the hospital's Medical Filing and Statistics Division and fully read, with a view to filling out the proposed data collection instruments.

The ISS and NISS were calculated on a printed instrument that permitted distributing injuries according to body region, the coding of injuries according to the AIS 2005 manual and the identification of the most severe injuries, in general for the calculation of the NISS and per body region for the ISS. For the final calculation of the SAPS II and LODS scores, the worksheets available on-line at http://www.sfar.org/scores2/saps2.html and http:/ /www.sfar.org/scores2/lods2.html were used, on which the obtained data were compiled, thus permitting the electronic calculation of these indices and of the patient's mortality risk.

NCSS for Windows was used to analyze and interpret results. With a view to assessing the predictive capacity of the ISS, NISS, SAPS II and LODS indices to foresee the dependent study variables (length of stay and mortality at ICU), Receiver Operating Characteristic (ROC) curves were constructed for each of the studied outcomes, obtaining accuracy, measure of the area under the curve (AUC) and confidence interval. The cut-off points obtained by the ROC curve simultaneously considered the best sensitivity and specificity with regard to the addressed variable.

As SAPS II and LODS results indicate both a total score and mortality risk, it should be highlighted that, in the construction of the ROC curves, mortality risk estimates were used. The comparative test of the areas under the curve was based on the $Z$ test. In all analyses, the significance level was set at $5 \%$ ( $p$ value $d " 5 \%$ ). Hosmer-Lemeshow's Goodness of Fit test was used to analyze the model's calibration, considered satisfactory when $p$ was $>0.05$.

\section{RESULTS}

The cases of 185 victims were considered. The results showed higher frequencies of young persons (mean age 38.95 years), male (76.76\%), who had been subject to surgery $(57.84 \%)$. The predominant external causes were traffic accidents $(63.79 \%)$, falls (15.13\%) and aggressions (11.90\%). The mortality rate at the ICU was $21.08 \%$ and, at the hospital, $21.62 \%$. The mean length of stay at the ICU was 16.55 days and, at the hospital, 21.71 days.

In the analysis of the severity index, $68.11 \%$ obtained mortality risk levels of less than $25 \%$ according to SAPS II. In line with this severity index, the number of victims decreased as the risk of death increased. Out of ten patients with mortality risk levels of $75 \%$ or higher as calculated by SAPS II, seven died, two were transferred to another institution and one was discharged. The mean mortality risk according to SAPS II was $22.85 \%$, with a standard deviation of $25.05 \%$ and median of $12.80 \%$. In terms of score, the mean SAPS II score was $34.10( \pm 17.52)$ and the median was 32, ranging from 6 to 86 points.

The behavior of the LODS was similar to that of the SAPS II: patients with mortality risk levels below $25 \%$ were more frequent and the number of victims decreased as the risk of death increased. Out of the ten patients in this research with death risk levels above $75 \%$, identified by the LODS, nine died and one was transferred to another institution. The mean mortality risk according to the LODS was $21.14 \%$, with a standard deviation of $22.47 \%$ and median $15 \%$. In terms of score, the LODS score was $4( \pm 3.48)$ and the median was 3 , ranging from 0 to 18 points. In 106 victims $(57.30 \%)$, the risk of death indicated by LODS was higher than by SAPS II. Mortality estimates by LODS and SAPS II did not coincide in any of the cases under analysis.

According to the ISS, victims scoring $<16$ totaled $38.38 \%$, between 16 and $24,37.30 \%$ and $\geq 25$, $24.32 \%$. Scores above 41 points were not identified in any of the victims. In total, 185 patient files were analyzed, of which 114 (61.62\%) victims presented important traumas, i.e. ISS $\geq 16$. The mean ISS found was 18.34 , with a standard deviation of 8.16 and a median of 17 .

When applying the NISS to the same victim group, $15.67 \%$ scored <16, 36.22\% between 16 and 24 and $48.11 \% \geq 25$. The victims' scores ranged from 2 to 48 points. Considering score 16 as an important trauma indicator, 156 patients $(84.33 \%)$ obtained higher NISS scores. The mean NISS found was 23.60 , the standard deviation was 8.89 and the median 24 points. Of all files analyzed in this research, $31.35 \%$ of victims obtained the same score on the ISS and NISS, while $68.65 \%$ scored higher on the latter than on the former. 
Table 1- Comparison between predictive capacity of ISS and NISS and between SAPS II and LODS for mortality at ICU, according to cut-off point, accuracy, area under the curve, confidence interval and HosmerLemeshow test. São Paulo, June to December 2006

\begin{tabular}{lccc}
\hline \multicolumn{4}{c}{ Mortality at ICU } \\
\hline ISS & NISS & $\mathbf{p}$ \\
Cut-off point & 18 & 25 & \\
Accuracy & $60 \%$ & $55 \%$ & \\
AUC & 0.63 & 0.58 & 0.073 \\
CI 95\% & $0.52-0.72$ & $0.47-0.67$ & \\
Hosmer-Lemeshow & $\mathrm{p}=0.6360$ & $\mathrm{p}=0.1683$ & \\
& SAPS II & LODS & $\mathbf{p}$ \\
Cut-off point & 39 & 5 & \\
Accuracy & $79 \%$ & $74 \%$ & \\
AUC & 0.85 & 0.83 & 0.1607 \\
CI 95\% & $0.76-0.91$ & $0.72-0.89$ & \\
Hosmer-Lemeshow & $\mathrm{p}=0.8870$ & $\mathrm{p}=0.0596$ & \\
\hline AUC: area under the curve; CI $95 \%$ : confidence interval at $95 \%$ &
\end{tabular}

Similar accuracy levels of the ISS and NISS were observed to predict mortality in ICU. Based on the $p$-value, no significant difference was found between the two areas under the curve. In the sample, the ISS and NISS did not present good discriminatory capacity for the occurrence of death at the ICU ( $A \cup C=0.63$ and 0.58), although Hosmer-Lemeshow's Goodness of Fit test indicated satisfactory calibration (pe"0.05) for the model.

As to the SAPS II and LODS, good accuracy was observed to predict mortality at ICU. The $p$-value showed no significant difference between the two areas under the curve. In He sample, however, SAPS II and LODS showed good discriminatory capacity for the occurrence of death at the ICU (AUC $=0.85$ and 0.83). Hosmer-Lemeshow's Goodness of Fit test also indicated satisfactory calibration for the model.

Table 2- Comparison between predictive capacity of ISS and NISS and between SAPS II and LODS for length of stay at ICU, according to cut-off point, accuracy, area under the curve, confidence interval and Hosmer-Lemeshow test. São Paulo, June to December 2006

\begin{tabular}{lccc}
\hline \multicolumn{4}{c}{ Length of stay at ICU } \\
\hline ISS & NISS & $\boldsymbol{P}$ \\
Cut-off point & 18 & 25 & \\
Accuracy & $58 \%$ & $63 \%$ & \\
AUC & 0.64 & 0.67 & 0.2529 \\
CI 95\% & $0.56-0.72$ & $0.59-0.74$ & \\
Hosmer-Lemeshow & $\mathrm{p}=0.5706$ & $\mathrm{p}=0.2484$ & \\
& SAPS II & LODS & $\boldsymbol{P}$ \\
Cut-off point & 32 & 4 & \\
Accuracy & $64 \%$ & $62 \%$ & \\
AUC & 0.63 & 0.63 & 0.7451 \\
CI 95\% & $0.54-0.71$ & $0.54-0.71$ & \\
Hosmer-Lemeshow & $\mathrm{p}=0.0000$ & $\mathrm{p}=0.0000$ & \\
\hline
\end{tabular}

AUC: area under the curve; CI $95 \%$ : confidence interval at $95 \%$
Similar accuracy levels were observed for the ISS and NISS to predict length of stay at ICU. According to the $p$-value, no significant difference was found between the two areas under the curve. In the sample, the ISS and NISS did not show good discriminatory capacity to predict length of stay at ICU ( $A \cup C=0.64$ and 0.67). Hosmer-Lemeshow's Goodness of Fit test indicated satisfactory calibration for the model.

When comparing SAPS II and LODS, similar accuracy was observed, an equal area under the curve, besides little discriminatory capacity to predict length of stay at ICU. Hosmer-Lemeshow's Goodness of Fit test indicated unsatisfactory calibration for the model.

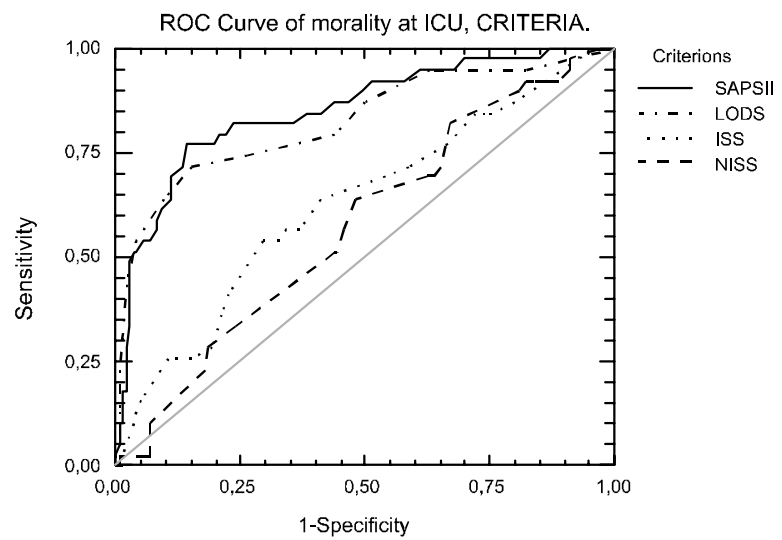

Figure 1- ROC curve of ISS, NISS, SAPS II and LODS indices for prediction of mortality at ICU. São Paulo, June to December 2006

According to the p-values, identified when comparing the areas under the curve, significant differences were found between ISS and SAPS II $(p=0.0002)$, ISS and LODS $(p=0.0011)$, NISS and SAPS II $(p=0.0000)$ and NISS and LODS $(p=0.0000)$ to predict mortality at ICU. It was observed in the ROC curve (Figure 1) that the areas of the SAPS II and LODS were significantly larger than those of the ISS and NISS. Therefore, SAPS II and LODS were considered better predictors of mortality at ICU than ISS and NISS.

Figure 2 reveals that the ISS, NISS, SAPS II and LODS curves are very close when analyzing the length of stay at ICU. Therefore, it cannot be affirmed that one index is better than another to predict length of stay at this unit, but only that results are similar. 


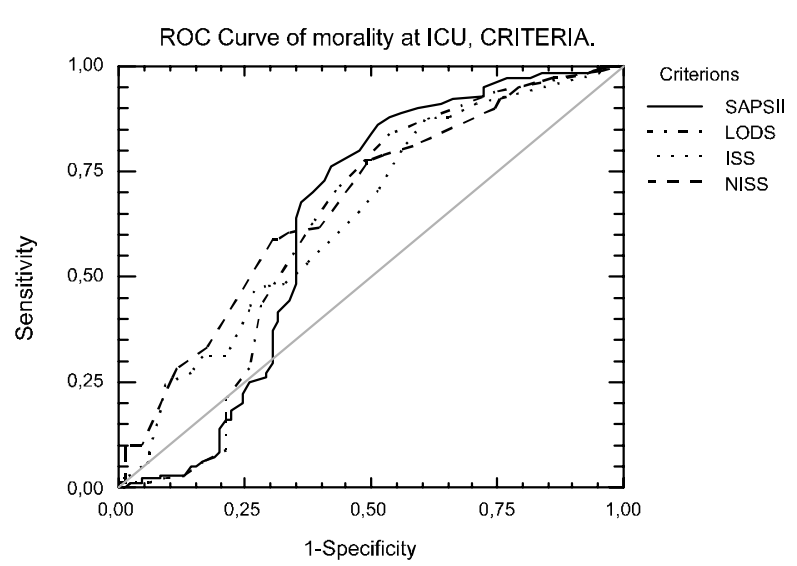

Figure 2 - ROC curve of ISS, NISS, SAPS II and LODS indices for prediction of length of stay at ICU. São Paulo, June to December 2006

\section{DISCUSSION}

In total, 185 files of trauma victims hospitalized at ICU were analyzed, 39 of whom died during their stay at the ICU, representing a mortality rate of $21.08 \%$ at the unit. International research on trauma victims in ICU reported on mortality rates ranging between 13.8 and $23 \%{ }^{(7-8)}$. A study on victims of traumatic brain injury identified hospital mortality rates of $20 \%$, and all victims who died had been admitted to the ICU at some time during hospitalization ${ }^{(9)}$.

Mean length of stay at the ICU (16.55 days) can be considered high in comparison with other studies. International research describing trauma victims at ICU indicated lower averages, between 4.9 and 10 days $^{(7,10-11)}$.

In this research, the mean score on the SAPS

II (34.10) approximates that in other international studies on trauma victims at ICU: $32^{(11)}, 36,6^{(7)}$. No studies were found in literature that used the LODS to identify the severity of trauma victims at ICU. Only one research used that index in trauma victims at the emergency room, with a mean score of five and mortality risk of $30 \%{ }^{(12)}$.

When applying the ISS to the group of trauma victims hospitalized at the ICU, the mean score was 18.34 and the median 17. More than half of the victims $(61.62 \%)$ showed ISS scores $\geq 16$. Research on trauma victims at ICU sometimes showed lower results, with a mean score of $6^{(13)}$ and a median of $9^{(14)}$, and at other times higher scores, with medians of $24^{(10)}$ and $25^{(7)}$. A Brazilian study revealed that $77.5 \%$ of 40 traumatic brain injury victims hospitalized at ICU scored $\geq 16$ on the ISS, as opposed to a minority of patients hospitalized at nursing wards reaching this severity levels $(7.50 \%)^{(9)}$.

The NISS has been continuously tested in comparison with the ISS and other indices. A literature review on research using the NISS in comparison with the ISS concluded that results favor the new version of the instrument, as most of the analyses evidenced the superiority of the NISS and none showed better performance for the ISS than for the NISS ${ }^{(5)}$.

In this study, neither the ISS nor the NISS showed good discriminatory capacity for mortality level and length of stay at ICU. Moreover, no significant difference was found between the two indices' AUC, neither for death risk nor for length of stay at ICU. Likewise, a research involving 10,062 patients in a database of trauma victims from different countries reveled similar performance for the NISS and ISS to predict length of stay at the $\mathrm{ICU}^{(10)}$. No studies were found in literature that compared these indices for mortality at ICU. However, hospital mortality is frequently analyzed as a variable for trauma victims in general. Most of those studies show better performance for the NISS to predict mortality/ survival.

SAPS II and LODS showed good discriminatory capacity to predict mortality levels of trauma victims, although the result was different when the outcome under analysis was length of stay at the unit. In literature, no similar comparisons were observed that used these two indices. However, a research of 11,021 traumatic brain injury victims admitted at ICU revealed that the SAPS II was a better predictor, with better calibration, than the Glasgow Coma Scale and the Acute Physiology and Chronic Health Evaluation (APACHE) II and III as for capacity to distinguish between survivors and non-survivors in the sample ${ }^{(8)}$.

The comparison of the four indices used in this research revealed that the SAPS II and LODS better predicted mortality at ICU than the ISS and NISS. In a study of 325 trauma victims admitted at ICU, patient survival was analyzed in the short and long terms. In that sample, the SAPS II also appeared as a better mortality predictor than the ISS in this group of victims ${ }^{(7)}$.

In the present study, however, none of the indices showed good capacity to predict hospitalization time at ICU. Hence, it should be reminded that the ISS and NISS are anatomy-based severity indices, while 
SAPS II and LODS are physiology-based, and that some studies have been proposing the combination of anatomic and physiological indices to improve accuracy levels when predicting the mortality of trauma victims $^{(15-16)}$. Perhaps this combination can also be a route to improve the accuracy of other outcomes, also related to these victims' length of stay at ICU.

In general, these research results evidenced better capacity of the SAPS II and LODS to predict mortality in trauma victims admitted at ICU than ISS and NISS, indicating that severity indices at ICU (SAPS II and LODS) should be preferred, even in trauma victims, when the goal is to predict mortality or assess care results at this unit in view of observed deaths. Moreover, the simplicity and speed to apply the SAPS II and LODS strengthen the use of these indices in trauma victims at ICU, as professionals working at the unit have little time available and instantly need to obtain information from patients with a view to clinical decision-making.

Finally, some limitations should be highlighted for the present research: it was carried out at a single institution that is a referral center for care delivery to trauma victims, not permitting the characterization of other populations. Besides, restrictions in terms of sample size, client type (adults only) and type of institution (university hospital) should be taken into account when applying or comparing the results. Hence, future research could broaden this study in terms of sample size and population diversity, and also carry out comparative analyses of different anatomy and physiology-based indices.

\section{REFERENCES}

1. Baker SP, O'Neill B, Haddon W, Long WB. The injury severity score: a method for describing patients with multiple injuries and evaluating emergency care. J Trauma 1974 March; 14(3):187-96.

2. Osler T, Baker SP, Long W. A modification of the injury severity score that both improves accuracy and simplifies scoring. J Trauma 1997 December; 43(6):922-5.

3. Le Gall JR, Lemeshow S, Saulnier F. A new Simplified Acute Physiology score (SAPS II) based on a European/North American multicenter study. JAMA 1993 December; 270(24):2957-63.

4. Le Gall JR, Klar J, Lemeshow S, Saulnier F, Alberti C, Artigas $A$, et al. The Logistic Organ Dysfunction system: a new way to assess organ dysfunction in the intensive care unit. JAMA 1996 September; 276(19):802-10.

5. Nogueira LS, Domingues CA, Campos MA, Sousa RMC. Tem years of New Injury Severity Score (NISS): is it a possible change?. Rev Latino-am Enfermagem 2008 marçoabril; 16(2):314-9.

6. Sousa RMC, Koizumi MS, Calil AM, Grossi SAA, Chaib L. A gravidade do trauma em vítimas de traumatismo crânioencefálico avaliada pelo manual AIS/90 e mapas CAIS/85. Rev Latino-am Enfermagem 1998 janeiro; 6(1):41-51.

7. Ulvik A, Wentzel-Larsen T, Flaatien H. Trauma patients in the intensive care: short-and long-term survival and predictors of 30-day mortality. Acta Anaesthesiol Scand 2007 February; 51(2):171-7.

8. Hyam JA, Welch CA, Harrison DA, Menon DK. Case mix, outcomes and comparison of risk prediction models for admissions to adult, general and specialist critical care units for head injury: a secorandy analysis of the ICNARC Case Mix Programme Database. Crit Care 2006 October;
10(Suppl 2):1-11.

9. Sousa RMC, Ferreira Júnior AA, Ikemori SY, Souza FF, Souza RC. Vítimas de trauma crânio-encefálico internadas em unidade de terapia intensiva e enfermaria de hospital de referência da Baixada Santista. Acta Paul Enferm 2004 abriljunho; 17(2):201-10.

10. Harwood PJ, Giannoudis PV, Probst C, Van Griensven M, Krettek C, Pape HC. Which AIS based scoring system is the best predictor of outcome in orthopaedic blunt trauma patients? J Trauma 2006 February; 60(2):334-40.

11. Seguin $P$, Laviolle $B$, Maurice A, Leclercq $C$, Mallédant $Y$. Atrial fibrillation in trauma patients requiring intensive care. Intensive Care Med 2006 March; 32(7):398-404.

12. Jones $A E$, Fitch $M T$, Kline JA. Operational performance of validated physiologic scoring systems for predicting in hospital mortality among critically ill emergency department patients. Crit Care Med 2005 May; 33(5):974-8.

13. Balogh ZJ, Varga E, Tomka J, Süveges G, Tóth L, Simonka JA. The new injury severity score is a better predictor of extended hospitalization and intensive care unit admission than the injury severity score in patients with multiple orthopaedic injuries. J Orthop Trauma 2003 August; $17(7): 508-12$.

14. Lavoie A, Moore L, LeSage N, Liberman M, Sampalis JS. The Injury Severity Score or the New Injury Severity Score for predicting intensive care unit admission and hospital length of stay?. Injury 2005 April; 36(4):477-83.

15. Reiter A, Mauritz W, Jordan B, Lang T, Põlzl A, Pelinka L, et al. Improving risk adjustment in critically ill trauma patients: the TRISS-SAPS score. J Trauma 2004 August; 57(2):375-80. 16. Kuhls DA, Malone DL, McCarter RJ, Napolitano LM. Predictors of mortality in adult trauma patients: the physiologic trauma score is equivalent to the trauma and injury severity score. J Am Coll Surg 2002 June; 194(6):695-704. 